\title{
A produção de redes na pesca artesanal como saber estruturante para o ensino de física escolar: diálogo de saberes no pibid educação do campo da UFPR litoral
}

The production of artisanal fishing net as a structuring knowledge for teaching school physics: dialogue of knowledge in PIBID rural education of UFPR litoral

Producción en red en pesca artesanal como conocimiento estructurador para la enseñanza de física escolar: diálogo de conocimientos en educación de campo pibid en UFPR litoral

João Marcos Gonçalves Haluch

André Luis Gonsalves Camilo Ehrick Eduardo Martins Melzer

Resumo: O presente artigo busca problematizar e apresentar uma prática pedagógica desenvolvida no âmbito do PIBID no NID Educação do Campo. O objetivo desta ação foi de construir em duas escolas do campo (Colégio Estadual do Campo Hiram Rolim Lamas e Colégio Estadual do Campo Ilha das Peças) processos de diálogo de saberes entre os saberes tradicionais da pesca artesanal e da física escolar, mais especificamente sobre tração, leis de Newton e forças. Para desenvolver esta ação pedagógica nas unidades educacionais foram desenvolvidos 4 etapas. Estas consistiram em: i) planejamento da proposta; ii) organização e desenvolvimento da oficina de produção de redes; iii) desenvolvimento do diálogo de saberes nas escolas e iv) avaliação da proposta pedagógica. O objetivo maior da prática foi de construir a ponte entre o saber da rede na pesca artesanal com os saberes da física escolar. Outro ponto que foi desenvolvido na prática foi a conscientização dos estudantes sobre a história da pesca artesanal e seu lugar como prática identitária caiçara. Ao final da ação, materiais pedagógicos foram produzidos para possibilitar a continuidade dos trabalhos pelos professores nas duas escolas. Em nossa avaliação coletiva com as escolas percebemos o envolvimento dos estudantes com a produção de redes e a construção da curiosidade epistemológica em torno dos saberes sobre a física. Neste sentido, avaliamos a proposta de construção do diálogo de saberes como potencial na descolonização dos saberes físicos tradicionais trabalhados na escola. Buscando harmonizar o aprendizado da ciência sem que se perca a identidade comunitária camponesa.

Palavras-chave: Educação do Campo, Ensino de Ciências, Física, Pesca Artesanal, Diálogo de Saberes.

Abstract: This article seeks to problematize and present a pedagogical practice developed within the scope of PIBID at NID Educação do Campo. The objective of this action was to build in two schools in the countryside (Colégio Estadual do Campo Hiram Rolim Lamas and Colégio Estadual do Campo Ilha das Peças) knowledge dialogue processes between the traditional knowledge of artisanal fishing and school physics, more specifically on traction, Newton's laws and forces. To develop this pedagogical action in educational units, 4 stages were developed. These consisted of: i) proposal planning; ii) organization and development of the network production workshop; iii) development of the knowledge dialogue in schools and iv) evaluation of the pedagogical proposal. The main objective of the practice was to build the bridge between the knowledge of the net in artisanal fishing and the knowledge of school physics. Another point that was developed in practice was the students' awareness of the history of 
artisanal fishing and its place as a caiçara identity practice. At the end of the action, teaching materials were produced to enable teachers to continue their work in the two schools. In our collective evaluation with the schools, we noticed the involvement of students in the production of networks and the construction of epistemological curiosity around knowledge about physics. In this sense, we evaluate the proposal to build the knowledge dialogue as a potential to decolonize the traditional physical knowledge worked at school. Seeking to harmonize the learning of science without losing the peasant community identity.

Keywords: Rural Education, Science Teaching, Physics, Artisanal Fisheries, Knowledge Dialogue.

Resumen: Este artículo busca problematizar y presentar una práctica pedagógica desarrollada en el ámbito de PIBID en NID Educação do Campo. El objetivo de esta acción fue construir en dos escuelas del campo (Colégio Estadual do Campo Hiram Rolim Lamas y Colégio Estadual do Campo Ilha das Peças) procesos de diálogo de conocimientos entre el conocimiento tradicional de la pesca artesanal y la física escolar, más específicamente sobre tracción. , Leyes y fuerzas de Newton. Para desarrollar esta acción pedagógica en unidades educativas, se desarrollaron 4 etapas. Estos consistieron en: i) planificación de propuestas; ii) organización y desarrollo del taller de producción de redes; iii) desarrollo del diálogo de conocimientos en las escuelas y iv) evaluación de la propuesta pedagógica. El objetivo principal de la práctica fue construir el puente entre el conocimiento de la red en la pesca artesanal y el conocimiento de la física escolar. Otro punto que se desarrolló en la práctica fue la conciencia de los estudiantes sobre la historia de la pesca artesanal y su lugar como práctica de identidad caiçara. Al final de la acción, se produjeron materiales pedagógicos para que los docentes pudieran continuar su trabajo en las dos escuelas. En nuestra evaluación colectiva con las escuelas, notamos el involucramiento de los estudiantes en la producción de redes y la construcción de curiosidad epistemológica en torno al conocimiento sobre física. En este sentido, evaluamos la propuesta de construir el diálogo de saberes como potencial para descolonizar el saber físico tradicional trabajado en la escuela. Buscando armonizar el aprendizaje de la ciencia sin perder la identidad de la comunidad campesina.

Palabras clave: Educación Rural, Enseñanza de las Ciencias, Física, Pesca Artesanal, Diálogo del Conocimiento.

\section{Introdução}

Este trabalho busca apresentar uma ação desenvolvida dentro do contexto do Programa Interinstitucional de Bolsas de Iniciação a Docência (PIBID), edital 2018-2020, dentro do Núcleo de Iniciação a Docência (NID) da Licenciatura em Educação do Campo: Ciências da Natureza (LECAMPO) da Universidade Federal do Paraná (UFPR). Este NID teve foco nas abordagens em educação científica aliada a estratégias do diálogo de saberes e a ecologia de saberes por meio das abordagens decoloniais e das abordagens das epistemologias do sul. 
Neste sentido, aqui trazemos um recorte de um dos projetos envolvidos com um grupo de bolsistas, moradores das ilhas do litoral paranaense e pescadores artesanais. A grande questão que foi colocada por este grupo foi a de: como a pesca artesanal com suas práticas ancestrais pode dialogar com o ensino de física na escola do campo?

A partir deste questionamento foi construído um processo de desenvolvimento de uma estratégia de ensino de ciências focada na práxis (articulação teoria e prática) com a construção de um diálogo de saberes voltado ao histórico da pesca artesanal por meio da prática da tecelagem de redes com o ensino de física nos conteúdos escolares de tração em cordas observados na trama da rede e resistência dos materiais no exame dos diferentes tipos de linhas de pesca e nylon.

A ação contou com três momentos distintos: i) planejamento e pesquisa sobre a temática com o levantamento dos saberes comunitários que os bolsistas (pescadores artesanais) já detinham. Este planejamento se organizou no formato de uma oficina. ii) desenvolvimento das atividades com uma oficina oferecida aos estudantes do Colégio Estadual Hiram Rolim Lamas em AntoninaPR sobre a tecelagem de redes para a pesca artesanal. iii) abordagem do histórico dos conflitos socio-ambientais em torno das práticas comunitárias de pesca artesanal no litoral paranaense, bem como discussão da centralidade do Movimento dos Pescadores Artesanais (MOPEAR) nesta luta pelo reconhecimento do Estado das práticas de pesca artesanais. Junto a esta discussão socioambiental também se fez a relação da física com o processo de construção das redes de pesca, construindo uma estratégia de diálogo de saberes e debate de poderes.

Vale ressaltar que todas as práticas desenvolvidas decantaram em três produtos pedagógicos: a) um material escrito sobre a pesca artesanal e os conflitos socioambientais no litoral paranaense. b) um kit de ensino da tecelagem de redes contendo: agulha própria, malha e linha para o ensino do saber comunitário. c) um pôster sobre a relação saber da rede de pesca artesanal com a física escolar dentro de uma proposta de diálogo de saberes. 
Este projeto é parte do PIBID e contou com o apoio financeiro da CAPES na manutenção das bolsas de supervisão e orientação a iniciação a docência. Também contamos com apoio do projeto Pró-licenciaturas que forneceu recursos para aquisição dos materiais para confecção dos kits para serem usados na oficina. Desta forma, agradecemos a CAPES pelo apoio no desenvolvimento desta atividade de ensino, pesquisa e extensão através da iniciação a docência dos professores de educação do campo.

Assim, este artigo organiza-se nas seguintes seções: i) uma contextualização do projeto PIBID NID Educação do Campo com seu formato de funcionamento, abrangência social e territorial. ii) Uma fundamentação teórica sobre o diálogo de saberes na ótica da ecologia de saberes (SANTOS, 2003 e 2007) e no debate de poderes (QUIJANO, 2005) que deram base a construção da proposta pedagógica, bem como uma contextualização da pesca artesanal e de seus conflitos ambientais com no estado do Paraná. iii) a apresentação da proposta pedagógica construída para desenvolvimento no Colégio Estadual do Campo Hiram Rolim Lamas que fica localizado na Vila da Copel no município de Antonina e no Colégio Estadual do Campo Ilha das Peças, Içocalizado na Ilha das Peças, Guaraqueçaba, ambos municipios do litoral paranaense. iv) uma análise do diálogo de saberes construído na prática da tecelagem de redes, bem como a discussão sobre os conflitos sócio-ambientais referentes a pesca artesanal no litoral do Paraná.

\section{O PIBID Educação Do Campo da UFPR Litoral}

O PIBID historicamente foi uma política educacional constituída como uma estratégia para reforçar o estímulo da formação de professores em licenciaturas de todo o país. A ideia central é fazer um paralelo com o Programa Interinstitucional de Bolsas de Iniciação Científica (PIBIC) no sentido de propiciar um incremento a formação inicial do professor, assim como temos a do pesquisador, pela CAPES. O grande diferencial nas primeiras edições foram os diferentes níveis de bolsa (bolsista, supervisor, coordenador e coordenador institucional) e a possibilidade de uma verba de custeio para as atividades de ensino, pesquisa e extensão no âmbito das licenciaturas. Porém, com as 
mudanças no cenário político nacional, as pressões dos empresários da educação (FREITAS, 2014) e os movimentos conservadores e do mercado educacional, forçaram a cortes de recursos para esta ação e paulatinamente a cada edição houve diminuição de bolsas, corte de verbas de custeio. Ou seja, aos poucos o PIBID foi perdendo força e sendo descaraterizado pelas forças atuantes dentro do estado e com fortes interesses privado, uma espécie de criptogoverno como colocado por Bobbio (2015).

Ressalta-se que o Movimento por Educação do Campo para apoio a formação das Licenciaturas em Educação do Campo (LEDOCS) nas diferentes áreas de conhecimento e formação pleitaram via SECADI a criação de um PIBID específico as necessidades da alternância pedagógica e territorial da Educação do Campo. Este programa foi nomeado de PIBID Diversidade, porém, infelizmente esta versão do PIBID foi descontinuada. Nos editais mais recentes do PIBID, por muita pressão das LEDOCS, foi inserido as licenciaturas em educação do campo.

A grande contradição nos editais se fazem no sentido da CAPES incompreender a formação por área de conhecimento e as particularidades sócio territoriais da educação do campo e da prática do regime de alternância pedagógica. É neste clima que nasce o projeto do PIBID Educação do Campo da UFPR no edital 2018-2020, construindo processos que vão além do edital e que potencializaram o maior atendimento de demandas a partir da relação Tempo Universidade (TU) com ações nas escolas selecionadas pelo PIBID e no Tempo Comunidade (TC) com ações em outras unidades educacionais presentes nas comunidades de origem dos bolsistas.

Assim, o PIBID NID Educação do Campo organiza-se em duas unidades educacionais. Uma delas é localizada na zona rural do município de Antonina, dentro de uma unidade da Companhia Paranaense de Energia (COPEL). O Colégio Estadual do Campo Hiram Rolim Lamas atende estudantes de antonina e região. A segunda escola é o Colégio Estadual do Campo Ilha das Peças, localizado na llha das Peças e pertencente ao município de Guaraqueçaba.

Neste contexto, o referido NID foi constituído por dentro da proposta de Alternância pedagógica de tempos, como se organiza o curso da LECAMPO. 
Neste sentido, no TU se desenvolveram ações individuais e coletivas nas escolas Hiram Rolim Lamas e llha das Peças. Já no TC as ações foram nas comunidades de origem dos estudantes em outras escolas como relacionadas no quadro 1:

\begin{tabular}{|c|}
\hline Escolas PIBID - desenvolvimento de atividades no Tempo Universidade (TU) \\
\hline Colégio Estadual do Campo llha das Peças (Ilha das Peças, Guaraqueçaba-PR) \\
\hline Colégio Estadual do Campo Hiram Rolim Lamas (Vila da COPEL, Antonina-PR) \\
\hline $\begin{array}{c}\text { Escolas nas Comunidades - desenvolvimento de atividade no Tempo } \\
\text { Comunidade }\end{array}$ \\
\hline Colégio Estadual Indígena Mbyá Arandú (Aldeia Araçaí, Piraquara-PR) \\
\hline Colégio Estadual Quilombola Diogo Ramos (Quilombo João Surá, Adrianópolis-PR) \\
\hline Colégio Estadual do Campo de Lagoa (Tijucas do Sul-PR) \\
\hline Secretária Municipal de Educação de Tijucas do Sul \\
\hline Escola Estadual Assentamento Zumbi dos Palmares (Iporanga-SP) \\
\hline Escola Estadual Rosaria Januzzi (Apiaí-SP) \\
\hline
\end{tabular}

Quadro 1: escolas selecionadas para desenvolvimento do NID Educação do Campo. Fonte: Autores (2020).

Para se ter uma ideia o mapa a seguir dá uma noção da abrangência territorial das ações do PIBID Educação do Campo: 


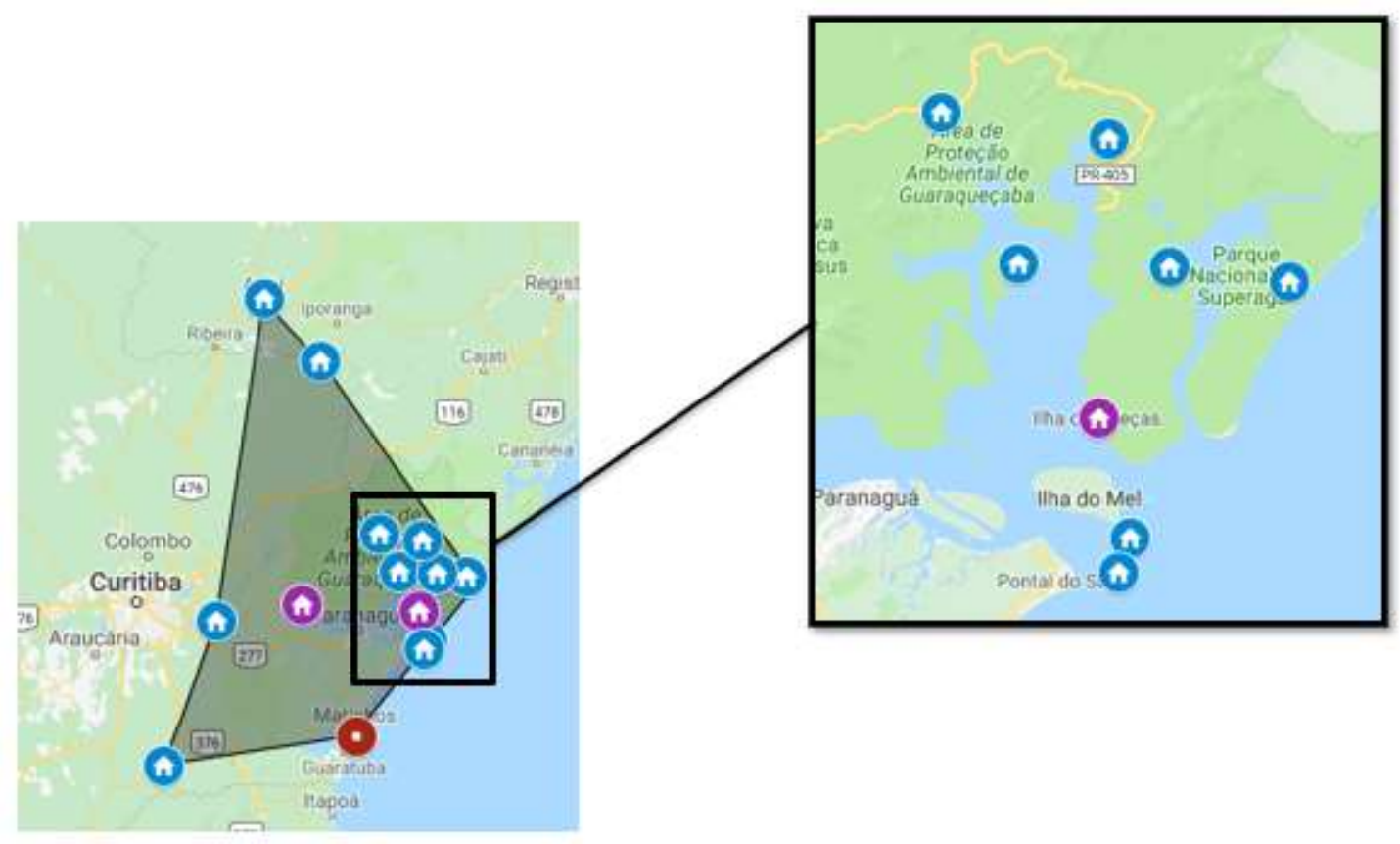

FIGURA 1: Mapa de abrangência territorial do PIBID Educação do Campo.

Fonte: elaboração do autor no GOOGLE My Maps.

Na composição do coletivo de bolsistas o PIBID Educação do Campo contou com Quilombolas do Vale do Ribeira do Quilombo João Surá, localizado em Adrianópolis. Pescadores artesanais e moradores das ilhas do Mel, Rasa, Cotinga e das Peças no Litoral do Paraná. Contou com moradores da zona rural de Morretes, Antonina e Guaraqueçaba. Também contou com estudantes moradores do primeiro anel metropolitano de Curitiba nos municípios de Piraquara e Tijucas do Sul. Também teve estudantes indígenas da Aldeia Araçaí e contou com a participação de estudantes moradores de comunidades rurais e assentamentos da reforma agrária nos municípios de Apiaí e Itaoca no estado de São Paulo. Uma marca positiva deste projeto foi a grande diversidade territorial e de pensamento e construção de mundo que deu margem a construção de tráfego de saberes intercomunitários nas propostas do projeto.

O diálogo de saberes, educação do campo e a pesca artesanal no litoral Paranaense

Historicamente, a Educação do Campo se constrói dentro da ação questionadora da realidade do movimento social. Nasce dos debates em torno 
de educação do no interior das bases do Movimento dos Trabalhadores Sem Terra (MST), pois, a pauta do momento era de garantir o direito a educação de crianças, jovens e adultos nos acampamentos e assentamentos da reforma agrária popular.

Assim, a Educação do Campo nasce da luta das pessoas residentes no campo por melhores condições educacionais e, prioritariamente, em contraposição a um processo histórico de um projeto educacional que visou um campo sem pessoas como espaço para especulação produtiva do Agronegócio. A este movimento histórico podemos compreendê-lo como a Educação Rural.

Neste sentido como colocado por Caldart (2010) a Educação é "no" campo e "do", pois, trata de se constituir no território de vida e produção de existência do camponês e também é feita do camponês para o camponês.

Outro ponto que cabe destacar é a noção de campo e camponês. Nos primórdios da Educação do Campo, o olhar estético, epistemológico e ontológico era focado no assentado e acampado sem terra. A partir das experiências de outros movimentos sociais que adentraram a luta por Educação do Campo e também das Universidades por meio de seus cursos voltados a formação de professores por meio do PROCAMPO; houve um alargamento conceitual de campo e de camponês.

Neste sentido, compreendemos que a Educação do Campo é feita no debate da diversidade de populações e também de formas de viver, crenças e de produção da sua existência. Seja em territórios de terra ou de água, o camponês é aquele que vive tradicionalmente e de uma forma ontológica única no seu território. Ou seja, não podemos separar o camponês do seu campo, o sujeito do seu território, seja este território de terra ou de água.

Por isso que de acordo com Fernandes e Molina (2016) o território é a unidade fundamental e o que dá identidade ao camponês e também a escola do campo. Então, neste artigo compreendo que o camponês é aquele que tem uma relação única com a terra ou as aguás, seu território, do qual produz sua vida e sua história como trabalhador. Neste debate podemos incluir: acampados, assentados, produtores rurais, produtores familiares, quilombolas, caboclos, faxinalenses, pescadores artesanais, ribeirinhos, faxinalenses, indígenas, 
ciganos e tantas outras populações que vivem e produzem sua existência da terra e da água, sendo em locais fixos ou em movimentos migratório.

Também não podemos deixar de lado que a Educação do Campo tem uma dupla determinação conceitual histórica. Uma adquirida do seio do movimento social e balizada nas experiências emancipadores dos movimentos por educação popular em todo o Brasil, tendo como um dos expoentes dessa produção os movimentos de alfabetização conduzido por Paulo Freire (FAVERO, 1983). A outra é constituída a partir da luta e militância do MST a frente da conquista do Programa Nacional de Educação na Reforma Agrária (PRONERA), originando o Movimento por Uma Educação do Campo (MUNARIM, 2011). Foi este movimento que determinou a inserção da Educação do Campo enquanto pauta do governo e, assim, a inseriu como modalidade educacional na Lei de Diretrizes e Bases da Educação Nacional 9.394 de 1996 (LDBEN 9.394/1996). Neste sentido, esta dupla determinação que é popular e legal. Popular pela sua gênese na luta dos Movimentos Sociais e legal devido a sua transição para a lei e para a conquista do direito à educação dos povos do campo que fazem como um movimento educacional importante no país e único.

Desta forma, Educação do Campo é antes de tudo um projeto contrahegemonico de sociedade e de campo, pensado numa relação harmônica com os movimentos insurgentes contra o sistema capitalista de produção e os processos de individualização próprios da sociedade burguesa. Neste sentido, Educação do Campo é a luta por processos educativos emancipadores que tem como base a compreensão da coletividade e do trabalho socialmente necessário como fatores fundantes da realidade humana (PISTRAK, 2015; KRUPSKAYA, 2017).

Ao longo da história e debates em torno da Educação do Campo, também se viu a necessidade de trabalhar na escola do campo, outras formas de uso da terra e produção da existência. Neste sentido, que nos últimos anos, os movimentos sociais, universidades, coletivos que trabalham com Educação do Campo, buscaram aproximar o debate da Agroecologia.

A Agroecologia busca trazer o debate de modos de produção mais saudáveis, mas acima de tudo, desenvolve o debate em torno do modelo de 
produção, da forma de ver a vida e a sociedade e busca trazer a relação do novo (moderno) e parceria com o antigo produzindo maior qualidade alimentar e saúde.

Caporal (2004) coloca que não se pode pensar a Agroecologia por fragmentos. Esta deve ser compreendida em relação a uma complexidade, a uma visão sistêmica da realidade, no que ele denomina de agroecossistema. Neste sentido é a junção das diferentes dimensões que se forma o sistema complexo, pelo qual busca-se se produzir sem veneno (agrotóxicos), com qualidade, diversidade e respeitando o conhecimento originário produzido pela tradição oral.

Assim, um dos pilares da Agroecologia está no que os teóricos decoloniais e as epistemologias do sul denominam como Diálogo de Saberes. Esta forma de pensar, de interagir com a produção do conhecimento, parte do pressuposto que o conhecimento socialmente aceito nos processos de ensino-aprendizagem não é aquele somente produzido pelo método científico. Esta proposta busca afirmar a importância dos saberes locais, comunitários, como forma de existir e de produzir a identidade da comunidade.

Neste sentido, há de se entender que dentro dos estudos decoloniais há duas posições nos processos de construção de proposta anti-coloniais. O primeiro baseia na negação de tudo que é produzido pelo norte global, colocando as nações subalternizadas, os povos do Sul, como produtores de saberes, culturas e de ciência. O saber comunitário é visto como ciência, pois foi produzido a partir de um método coletivo e histórico. A outra posição busca construir novos processos de conhecimento a partir de uma relação dialética na produção de saberes decolonizados. Ou seja, a segundo posição não nega o saber eurocêntrico e branco, mas busca no diálogo com o conhecimento comunitário ressignificá-lo e utilizá-lo como instrumento de emancipação e de identificação dos povos e comunidades. É nesta segunda linha de pensamento que nasce e se constitui a proposta da Ecologia de Saberes ou do Diálogo de Saberes.

Partindo deste princípio a Ecologia de Saberes como colocado por Santos (2003 e 2007) põe em patamares equivalentes os saberes científicos, 
construídos na tradição científica colonizadora da Europa, com os saberes comunitários, construídos no seio das comunidades dentro do processo de passagem oral de uma geração a outra.

Analogamente, a Agroecologia também trabalha com este princípio dentro do diálogo de saberes. Através da pesquisa participa busca-se inventariar tais práticas passadas através de gerações e organizá-las como base de conhecimento reconhecida localmente com os saberes traduzidos e construídos pela ciência em escala global (ALTIERI, 2002).

A partir desta compreensão, na Agroecologia, traça-se quatro principios básicos para o diálogo de saberes e o ensino de base agroecológica nas escolas camponesas: i) princípio da vida; ii) princípio da diversidade; iii) princípio da complexidade e iv) princípio da transformação (ABA, 2012). Ou seja, é a partir da compreensão da comunidade e do agroecossistema que torna-se possível o estabelecimento do diálogo de saberes e culturas.

Quando olhamos para o território do litoral do Paraná percebe-se que neste há uma complexa baia formada por um arquipélago de ilhas. Este espaço tem sido historicamente o território das águas dos moradores das ilhas no ofício da pesca artesanal. Porém, o poder publico junto a iniciativa privada e os órgão ambientais, nas últimas décadas têm criminalizado as técnicas tradicionais de pesca artesanal, retirando o sustento de inúmeras famílias. Forçando-as a abandonar as ilhas para viver no continente. É a partir desta situação de opressão por meio da força policial que os pescadores, a partir de formações políticas, decidem se organizar em torno da constituição de um movimentos social de luta e resistência dos pescadores artesanais. A este grupo nomeou-se de MOPEAR que tem tido uma atuação constante para a garantia da legitimidade dos saberes e fazeres dos pescadores artesanais.

Neste sentido, compreende-se que é salutar o desenvolvimento de estratégias pautadas no Diálogo de Saberes que tem como intuito de transmitir conhecimento científico aliado aos saberes comunitários dos povos das águas e florestas para a construção de processos em Educação do Campo mais humanos e mais diversos. 


\section{A produção da proposta didática}

A construção da proposta didática foi organizada em quatro momentos distintos, sendo: i) planejamento da proposta; ii) organização e desenvolvimento da oficina de produção de redes; iii) desenvolvimento do diálogo de saberes nas escolas e iv) avaliação da proposta pedagógica.

$\mathrm{Na}$ primeira etapa foi desenvolvida em reuniões entre os bolsistas, professores supervisores, direção pedagógica da escola e coordenação do Núcleo de Iniciação a Docência (NID). Estas reuniões foram feitas dentro da unidade educacional com 0 intuito de explicar o desenvolvimento dos planejamentos organizados pelos bolsistas e para possíveis ajustes com professores supervisores e direção no sentido de organizar os conteúdos pedagógicos da física que seriam trabalhados e como estes se desenvolveriam no desenrolar da proposta em questão. Neste planejamento foi construído um calendário com as atividades pedagógicas previstas para 0 seu desenvolvimento.

Na segunda etapa, consistiu numa organização de uma oficina sobre confecção de redes dentro da pesca artesanal. Esta oficina foi pensada na seguinte estrutura: a) apresentação da oficina; b) explicação histórica da pesca artesanal e c) confecção de redes.

O desenvolvimento da proposta da oficina foi deixada a cargo de dois bolsistas PIBID pescadores artesanais que fizeram a apresentação do curso de licenciatura em educação do campo e das comunidades de pescadores artesanais a que pertencem. Foi explicado para os estudantes o objetivo da oficina e quais saberes comunitários da pesca artesanal seriam mobilizados. $\mathrm{Na}$ sequência, foi apresentada uma história da pesca artesanal no litoral do Paraná e o papel da rede de pesca no ofício do pescador artesanal. Findada esta primeira etapa com a apresentação da oficina (a) e explicação histórica da pesca artesanal (b) foi encaminhado ao aprendizado coletivo em roda da confecção das redes de pesca artesanal.

No processo de confecção das redes foi utilizado um instrumento que constitui de linha, agulha e uma peça de madeira para fazer a organização da trama da rede, conforme imagem do modelo de agulha utilizada: 


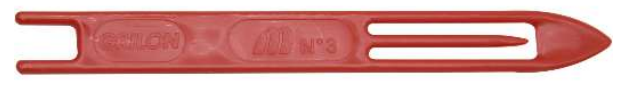

FIGURA 2: Agulha para tecelagem de redes.

Fonte: https://www.bartofil.com.br/site/empresas/fotosprodutos/1500x1500/103600_a.jpg

A partir da introdução ao tema, os discentes bolsistas PIBID explicaram o funcionamento das ferramentas para construção de rede, iniciando o processo coletivo com os estudantes de confecção de redes de pesca artesanal, conforme figura 3:

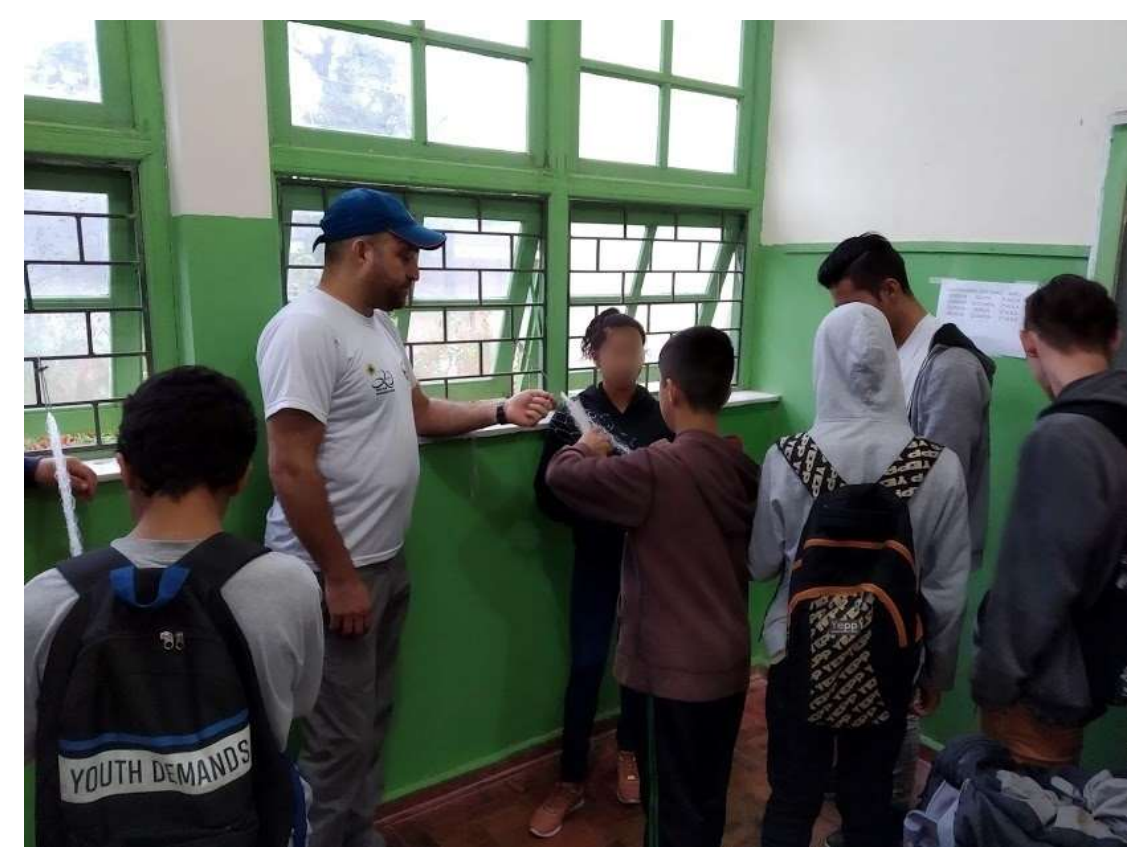

FIGURA 3: Confecção de redes no dia da oficina no Colégio Estadual do Campo Hiram Rolim Lamas.

Fonte: os autores (2020).

A terceira etapa procedeu com aulas de física que trabalharam com os saberes na produção das redes para a pesca artesanal. Desta forma, os saberes foram organizados para cada faixa etária de acordo com o nível de complexidade exigido para cada grupo de estudantes. Para os estudantes de ensino fundamento $\left(6^{\circ}\right.$ a $9^{\circ}$ anos) foram trabalhados com conceitos mais simples sobre resistência de materiais e tensão. Ou seja, desenvolveu-se noções básica sobre o tema. Já Com os estudantes do ensino médio foram trabalhados conceitos de 
física imersos dentro cinemática com o cálculo de forças, tração, peso, leis de Newton, dentre outros conceitos físicos.

Esta etapa foi desenvolvida no momento de sala de aula com as turmas, buscando trabalhar conceitos de física com a supervisão do professor responsável pela ação do PIBID em cada uma das escolas. Ao todo foram usadas duas aulas em cada escola para desenvolvimento dos saberes física em torno de cordas e forças.

A quarta etapa foi composta de uma avaliação coletiva feita com os bolsistas, professores supervisores, direções e coordenadores do PIBID. A ideia deste último momento foi compreender os avanços, limites e possibilidades de aprimoramento da proposta.

Nas duas escolas (Colégio Estadual do Campo Hiram Rolim Lamas e Colégio Estadual do Campo Ilha das Peças) todos os estudantes do Ensino Fundamental II e Médio foram mobilizados, pois, estas escolas contam com poucos estudantes por turma permitindo um trabalho mais integrado no desenvolvimento da proposta do PIBID. Ao final da proposta as escolas também tiveram acesso a um material escrito sobre pesca artesanal, pôster produzido pelos bolsistas do projeto como material de apoio as aulas no processo de diálogo de saberes e um kit contendo linha e agulha para produção de redes da pesca artesanal.

\section{Diálogo de saberes no ensino de física na produção de redes}

Neste processo pedagógico da construção da prática pedagógica no PIBID constata-se que a construção do Diálogo de Saberes se deu no processo de apresentação do ofício da pesca artesanal, no processo de confecção de redes de pesca com os saberes físicos sobre força de tração e deformação e resistência das linhas.

Foi a partir do processo de tear as redes de pesca que os bolsistas com o professor supervisor do PIBID puderam trazer, em sala de aula, conceitos sobre a força de tração que é feita na trama da rede ao fazer o empuxo na água. Desenvolvendo o conceito da $2^{\mathrm{a}}$ lei de Newton que enuncia que toda força é uma 
ação da massa de um corpo pela sua aceleração. Assim, foi possível calcular a força de tração exercida na trama da rede a partir da seguinte fórmula:

$$
T=m \cdot a
$$

Onde Tração (T) é calculada em Newtons $(\mathrm{N})$; a massa $(\mathrm{m})$ é a quantidade de pesca arrastada na rede que é calculada em Kilogramas (Kg) e que se relaciona com a aceleração (a) do barco ao arrastar a rede (RESNISCK e HALLIDAY, 1983).

Outro conceito que foi desenvolvido na relação de diálogo de saberes foi com relação a resistência das linhas. Buscou-se a partir da experimentação prática compreender as diferentes resistências das linhas de pesca, desde as mais finas até as mais grossas e suas utilizações em redes de pesca artesanal. Também foi trabalhado com a compreensão da linha de nylon, comumente utilizada em algumas redes. Buscando explicar aos estudantes as diferenças de resistência de cada material e também da grossura de cada linha, sendo que as linhas com maior diâmetro apresentam maior resistência a tração e consequentemente podem formar redes mais resistentes.

Desta forma, a partir desta prática criou-se um caminho epistemológico e pedagógica da prática partindo numa proposta de teoria com ação (práxis) com a explicação histórica da situação e dos conflitos que os pescadores artesanais no litoral do Paraná vem vivendo, o aprendizado da tecelagem da rede para a pesca artesanal e com o trabalho dos conceitos físicos de tração em cordas e de resistência de materiais com o exame de diferentes linhas de pesca e de nylon.

O que pode-se se perceber a partir do enlace saber tradicional, comunitário, e saber científico foi um envolvimento dos estudantes com os saberes, história e reconhecimento de suas raízes caiçaras nas técnicas da pesca artesanal. Muitos dos jovens que participaram das oficinas gostaram de aprender a tecer redes e levaram estes saberes para suas casas, como uma forma de desenvolvimento da relação escola com comunidade. O que também se percebeu nas aulas de física, a partir dos professores supervisores, foi um 
envolvimento com o conteúdo e a compreensão da sua aplicabilidade prática, no seu dia-a-dia, a partir da rede.

A partir de Freire (2005) podemos compreender que a rede foi um tema gerador que construiu a ponte do saber da pesca artesanal com a física escolar, fomentando a curiosidade epistemológica e trazendo significado (palavra mundo) a ação pedagógica das aulas de física.

Avaliamos que esta prática foi potencial e consistiu em uma construção de diálogo de saberes profícua, trazendo o trato do saber da comunidade com o saber científico e que muitas vezes é trabalhado abstratamente. Ou seja, a partir deste processo pedagógico e por meio do PIBID Educação do Campo pode-se construir um saber escolar dotado de porções da realidade e que traz ao jovem o reconhecimento de sua identidade e a importância do trabalho socialmente necessário.

\section{Considerações finais}

Este artigo teve como objetivo apresentar uma ação do PIBID NID Educação do Campo que contou com o apoio da Coordenação de Aperfeiçoamento de Pessoal de Nível Superior (CAPES). Salientamos que esta prática foi alicerçada ao longo da execução das atividades do PIBID, contando com a produção de material didático na forma de um encarte sobre pesca artesanal e o pôster pedagógico que foi impresso e distribuído nas escolas do campo parceiras. Além deste material impresso foi também disponibilizado para cada escola um conjunto de linhas de pesca e nylon, além de agulhas para tecelagem de redes de pesca artesanal. O material referente a esta prática pedagógica está sendo digitalizado e disponibilizado de forma digital por meio do portal PIBID Educação do Campo disponível no site do Laboratório de Estudos em Ludicidade, Tecnologia e Comunicação (LUTECOM) da Universidade Federal do Paraná (UFPR), Setor Litoral, no site: www.lutecom.ufpr.br.

Compreendemos que a prática pedagógica dentro do diálogo de saberes tornou possível a mediação de conteúdos físicos com os saberes comunitários e históricos da pesca artesanal por meio da história da luta dos pescadores no 
litoral do Paraná e na confecção de um instrumento tradicional do ofício do pescador que é a rede. Após a prática, no processo de avaliação, compreendemos outras possibilidades de exploração desta proposta para trabalho com outros conteúdos de física e também da química que estão sendo discutidos e aprimorados para novas práticas no diálogo de saberes da pesca artesanal com os saberes escolares científicos.

Também entendemos que a resposta para a pergunta lançada na introdução deste artigo se materializa no desdobramento desta prática como uma possibilidade prática de formação inicial e continuada de professores por meio do PIBID. Compreendemos que o diálogo de saberes desdobra-se como recurso potente para o ensino de ciências na escola do campo como elemento de adensamento da discussão política e social da realidade concreta dos estudantes.

Por final, destacamos que estas práticas na Escola do Campo ressignificam a relação dos saberes escolares com os saberes da comunidade; dando materialidade a proposta do Diálogo de Saberes que muitas vezes é colocadas nos estudos em ciências sociais e Agroecologia como propostas teóricas sem um caminho prático para desenvolvimento das experiências. Ressaltamos que é possível dentro do espaço escolar camponês relacionar saberes escolares científicos com os saberes comunitários em pé de igualdade, fazendo com que haja o fortalecimento da identidade comunitária e também a construção de uma visão de ciência mais popular e comunitária.

\section{Agradecimentos}

Fazemos um agradecimento a CAPES pelo incentivo e fomento por meio do PIBID com a concessão de verba de apoio e bolsas pedagógicas de estudantes, professores e coordenadores para o desenvolvimento desta atividade nas escolas citadas.

\section{Referências}

ALTIERI, M. Agroecologia: bases científicas para uma agricultura sustentável. Guaíba: AS-PTA/Agropecuária. 2002. 592p. 
ASSOCIAÇÃO BRASILEIRA DE AGROECOLOGIA - ABA. SEMINÁRIO NACIONAL DE EDUCAÇÃO EM AGROECOLOGIA: CONSTRUÍNDO PRINCÍPIOS E DIRETRIZES - I SNEA. Comissão organizadora I SNEA. Recife, PE. 2012.

BOBBIO, Norberto. Democracia e segredo. São Paulo: UNESP, 2015.

CALDART, R. S. A Educação do Campo e a perspectiva de transformação da forma escolar. In: Munarim, Antônio; Beltrame, Sônia; Conde, Soraya Franzoni; Peixer, Zilma Izabel. (Orgs.). Educação do Campo: reflexões e perspectivas. $1^{a}$ ed. Florianópolis: Insular, 2010, p. 145-187.

CAPORAL, F. R. \& COSTABEBER, J. A. Agroecologia: alguns conceitos e princípios. Brasília : MDA/SAF/DATER-IICA, 2004.

FÁVERO, O. Cultura popular educação popular: memória dos anos 60 . Rio de Janeiro: Graal, 1983.

FERNANDES, B. M. MOLINA, M. C. O campo da educação do campo. Disponível em: $<$ http://www2.fct.unesp.br/grupos/nera/publicacoes/ArtigoMonicaBernardoEC5. pdf>. Acesso em: 12 de maio de 2016.

FREITAS. L. C. de. Os empresários e a política educacional: como o proclamado direito à educação de qualidade é negado na prática pelos reformadores empresariais. Germinal: Marxismo e Educação em Debate, Salvador, v. 6, n. 1, p. 48-59, jun. 2014.

FREIRE, Paulo. Pedagogia do oprimido. São Paulo: Paz e Terra. 2005.

KRUPSKAYA, N. K. A construção a pedagogia socialista. São Paulo: Expressão Popular, 2017.

MUNARIM, A. Educação do campo no cenário das políticas públicas na primeira década do século 21. Em Aberto, Brasília, v. 24, n. 85, abr., p. 51-63, 2011.

PISTRAK, M. M. Ensaios sobre a escola politécnica. São Paulo: Expressão Popular. 2015.

QUIJANO, A. Colonialidade do poder, Eurocentrismo e América Latina. In: A colonialidade do saber: eurocentrismo e ciências sociais. Perspectivas latinoamericanas. Buenos Aires: Consejo Latinoamericano de Ciencias Sociales (CLACSO), 2005, p. 117-142.

RESNISCK, R. HALLIDAY, D. Física. 4ª Edição. Rio de Janeiro: LTC. 1983.

SANTOS, B. S. Para uma Sociologia das Ausências e uma Sociologia das Emergências. In: SANTOS, B. S. (Org.). Conhecimento prudente para uma vida decente: "Um discurso sobre as Ciências" revisitado. Porto: Afrontamento, 2003. p. 735-775. 
SANTOS, B. S. Para além do conhecimento abissal: das linhas globais a uma ecologia de saberes. Novos Estudos, V. 79, Nov, 2007.

\section{Sobre os autores}

João Marcos Gonçalves Haluch

jm-haluch@hotmail.com

Estudante do curso de Licenciatura em Educação do Campo: Ciências da Natureza da UFPR LITORAL. Pescador artesanal e lider comunitário na Associação de Moradores da llha do Mel. Residente na llha do Mel no Litoral do Paraná. Bolsista PIBID Educação do Campo na edição 2018-2020.

\section{André Luis Gonsalves Camilo}

luisandrecom34@gmail.com

Estudante do curso de Licenciatura em Educação do Campo: Ciências da Natureza da UFPR LITORAL. Pescador artesanal, morador da ilha do Superagui no Litoral do Paraná. Militante da luta pela Educação do Campo e pelos pescadores artesanais. Bolsista PIBID Educação do Campo na edição 20182020.

\section{Ehrick Eduardo Martins Melzer}

ehrickmelzer@ufpr.br

Licenciado em Química (2009), Mestre em Educação em Ciências e em Matemática (2012) e Doutor em Educação (2020) pela UFPR com tese de doutorado na análise da implementação do PROCAMPO. Atua em pesquisas com o ensino de ciências, educação do campo, políticas educacionais e diálogo de saberes. Docente colaborador do curso de Licenciatura em Educação do Campo: Ciências da Natureza (LECAMPO) e Vice coordenador da Licenciatura em Geografia (LIGEO) na UFPR Setor Litoral. Coordenador do Laboratório de Estudos em Ludicidade, Tecnologia e Comunicação (LUTECOM). 